\title{
BMJ Open Alcohol and drug use among adolescents: and the co-occurrence of mental health problems. Ung@hordaland, a population- based study
}

\author{
Jens Christoffer Skogen, ${ }^{1,2,3}$ Børge Sivertsen, ${ }^{1,4,5}$ Astri J Lundervold, ${ }^{5,6,7}$ \\ Kjell Morten Stormark, ${ }^{3}$ Reidar Jakobsen, ${ }^{3}$ Mari Hysing ${ }^{3}$
}

To cite: Skogen JC, Sivertsen B, Lundervold AJ, et al. Alcohol and drug use among adolescents: and the co-occurrence of mental health problems. Ung@hordaland, a population-based study. BMJ Open 2014;4:e005357. doi:10.1136/bmjopen-2014005357

- Prepublication history for this paper is available online. To view these files please visit the journal online (http://dx.doi.org/10.1136/ bmjopen-2014-005357).

Received 31 March 2014 Revised 1 August 2014 Accepted 18 August 2014

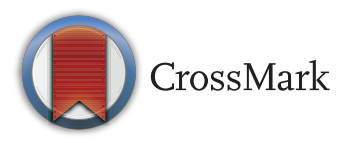

For numbered affiliations see end of article.

Correspondence to Dr Jens Christoffer Skogen; jens.skogen@uib.no

\section{ABSTRACT}

Objectives: The use of alcohol and drugs is prevalent among adolescents, but too little is known about the association between debut of alcohol and drug use, problematic use and concurrent mental health. The aim of the study was to investigate the cross-sectional association between debut of any alcohol or drug use and alcoholrelated and drug-related problems and mental health. We also wanted to examine potential interactions between gender and age, and alcohol-related and drug-related variables.

Design: Cross-sectional study.

Setting: Population-based sample of Norwegian adolescents.

Participants: Data stem from the large population-based ung@hordaland study ( $\mathrm{N}=9203)$, where all adolescents aged 17-19 years living in Hordaland county (Norway) were invited to participate. The main independent variables were debut of alcohol and drug use, alcohol consumption and the presence of alcohol and drug problems as measured by CRAFFT.

Outcomes: The dependent variables were self-reported symptoms of anxiety, depression, inattention and hyperactivity. Statistical analyses included logistic regression models.

Results: Debut of alcohol and drug use were associated with symptoms of depression, inattention and hyperactivity (crude ORs 1.69-2.38, $p<0.001$ ), while only debut of drug use was associated with increased symptoms of anxiety (OR=1.33, Cl 95\% 1.05 to 1.68 , $p=0.017$ ). Alcohol-related and drug-related problems as measured by CRAFFT were associated with all mental health problems (crude ORs 1.68-3.24, $p<0.001$ ). There was little evidence of any substantial age or gender confounding on the estimated associations between alcohol-related and drug-related measures and mental health problems.

Conclusions: Early debut of alcohol and drug use and drug problems is consistently associated with more symptoms of mental health problems, indicating that these factors are an important general indicator of mental health in adolescence.

\section{Strengths and limitations of this study}

This study employed a large well-defined population-based sample of adolescents.

- The data employed in this study are from a recent data collection.

- This study included several different measures of alcohol and drug use, as well as measures of both internalising and externalising problems.

- The cross-sectional design of this study precluded any causal inference.

- This study only had a limited age range; a wider range would enable a more thorough investigation of age-related effects of alcohol and drug use.

\section{BACKGROUND}

Previous studies of adolescents have found that a considerable proportion with one mental disorder also meet the criteria for at least one other mental disorder, including substance-use disorder. ${ }^{1-3}$ Furthermore, drug use and misuse have been related to a range of mental health problems, most consistently to externalising problems such as those associated with conduct disorder and attentiondeficit-hyperactivity disorder (ADHD) ${ }^{4}$ while the increased risk for anxiety disorders is lower. Also of note, several previous studies in adult populations have found that there is a J-shaped or U-shaped relationship between alcohol consumption and mental health outcomes, ${ }^{5-9}$ where abstainers and high-level alcohol consumers have increased risk for mental health problems. Several explanations of this curvilinear relationship have been suggested: moderate alcohol consumers may directly benefit from a protective effect on mental health from alcohol, or their drinking habits may be a mere reflection of their psychological well-being. ${ }^{6}$ Also, in cultures where 
alcohol use is the norm, moderate consumers may be more well adjusted than individuals at the extremes of the consumption spectrum. ${ }^{10}$ To date, few studies have investigated the relationship between the full spectrum of alcohol consumption (from non-debut to high-level alcohol consumption) and symptoms of mental health problems in a population-based sample of adolescents.

Boys have an earlier debut of alcohol consumption and intoxication according to most studies, ${ }^{11}$ while the gender pattern for onset of drug use is more unclear. ${ }^{12-17}$ The established gender differences with males using more alcohol and drugs seems, however, to be closing ${ }^{18}$ with recent studies not finding a higher rate of drug use among males. ${ }^{19}$ Whether the relation between alcohol and drug use and mental health is gender-specific is less clear. A lack of gender difference has been documented in population-based studies where the use of alcohol and drugs is associated with worse mental health. ${ }^{20-23}$ In contrast, some studies have reported a modifying effect of gender and age in relation to the association between alcohol use and mental health. ${ }^{21} 24{ }^{25}$ For instance, a study investigating the association between alcohol intoxications and mental health problems among 1319-year-olds found that high-level alcohol consumption was associated with conduct and attention problems for both genders, but only girls who reported frequent intoxication reported more symptoms of anxiety and depression. ${ }^{21}$ On the other hand, Verdurmen $e t a l^{24}$ reported a modifying effect of age on the association between alcohol use and mental health, but found no evidence of any modifying effects of gender. The association between alcohol use and mental health is, however, not quite consistent, as a Dutch study did not confirm the expected relation between binge drinking and mental health problems among 16-18-year-olds in a population-based study ${ }^{26}$ Furthermore, most of the previous studies have focused on drug and alcohol use, whereas little is known about the relationship between mental health and debut in adolescence.

In general, mental health problems show a consistent gender pattern in adolescence, with girls having a higher rate of depression and internalising problems, and boys a higher rate of externalising disorders. ${ }^{1}$ Little is known whether the association between drug use and mental health is gender-specific, but there are some indications that co-occurrence of other mental health problems are higher for girls than boys. ${ }^{4}$ However, in a sample of late adolescent urban youth, gender did not have a moderating effect on the relationship between substance abuse and mental health, and a Finnish study did not support a gender-specific association between depression and substance use. ${ }^{19} 27$

Also, it is uncertain if the co-occurrence is specifically related to alcohol or drug dependence or if it is also evident for mere alcohol or drug use. ${ }^{4}$ Overall, there is still a need for further investigation of the association between early alcohol and drug use and mental health in a general population of adolescents. ${ }^{28}$
To that end, the aim of the present study was to:

1. Describe the debut of alcohol and drug use, alcohol-use patterns and potential drug problems among Norwegian adolescents using data from a recent population-based study.

2. To investigate the cross-sectional relationship between (A) alcohol and illicit drug use and (B) alcohol and drug problems and mental health among adolescents. We also investigated any interactions with age and gender on the associations of interest, as well as the association between the full spectrum of alcohol consumption and frequency of drinking to intoxication in relation to mental health.

\section{METHODS}

\section{Study population}

This study employed information from the ung@hordaland study of adolescents in the county of Hordaland in western Norway. All adolescents born between 1993 and 1995 and living in Hordaland were invited to participate $(\mathrm{n}=19430)$, and 10220 participated, yielding a participation rate of 53\%. Ung@hordaland is a population-based study, carried out in close collaboration with the county council administration. The fourth wave of the longitudinal population-based study, 'Bergen Child Study', is also nested within ung@hordaland. The general aim of the ung@hordaland survey was to assess mental health, lifestyle, school performance and health-service use in adolescents, with a special emphasis on the prevalence of mental health problems. The data were collected during January-February 2012. Adolescents in upper secondary education received information per email, and one school hour was allocated for them to complete the questionnaire at school. Those not in school received information by mail to their home addresses. In addition, mental health facilities, juvenile detention centres and other institutions were contacted and the adolescents had the opportunity to participate. The questionnaire was web-based and covered a broad range of mental health issues, daily-life functioning, use of health and social services and demographic background variables. On participation electronic informed consent was obtained. Hordaland county is generally regarded representative of Norway as a whole, comprising the second largest city of Norway (Bergen) as well as large rural areas. Official statistics of the general population (not just adolescents) show that Hordaland county does not deviate in any substantial degree from the national average on key parameters, including sociodemographic indicators and several health indicators.

The current study is based on the first version of data files released in May 2012, with a total of 10220 participants. Based on list-wise deletion of those with missing information on independent and dependent variables, $\mathrm{n}=1017$ were excluded, leaving 9203 in the final study sample. Those with missing information on the variables of interest were slightly younger than those with valid information on the included variables (mean difference 
0.12 years, $\mathrm{p}<0.001)$ and more likely to be males $(61.6 \%$ versus $45.7 \%$ in the analysed sample, $\mathrm{p}<0.001$ ).

\section{Demographic information}

Information about age and gender was obtained on all participants. Furthermore, the participants indicated the perceived family socioeconomic status (SES) as (1) 'about the same as others' $(67.9 \%)$, (2) 'better than others' $(25.1 \%)$ or $(3)$ 'worse than others' $(7.1 \%)$, with $\mathrm{n}=172$ missing responses recoded to 'about the same as others'.

\section{Identification of alcohol problems and illicit drug use}

Self-reported debut, frequency and amount of alcohol consumption and illicit drug use were included as main independent variables. We included a binary measure of alcohol debut "Have you ever tried alcohol?" (Yes/No), and illicit drug-use debut: "Have you ever tried hash, marihuana or other narcotic substances?" (Yes/No). Out of the total study sample, $\mathrm{n}=11$ individuals did not answer the question on illicit drug use, and they were recorded in the 'No' category. Alcohol use was measured using the self-reported units of beer, cider, wine, spirits and illegally distilled spirits usually consumed during the past 14 days. Based on this information about consumption and alcohol debut, a summed variable on genderspecific distributions was constructed: 'Never tried', 'Non-consumption' (if reported consumption was ' 0 '), '0.1-19.9th', '20.0-79.9th', '80.0-89.9th', '90.0-100th'. Excessive alcohol consumption was defined as above the 90th centile sum score. ${ }^{8}{ }^{29}$ Frequent intoxication (binge drinking) was defined as drinking so much that one was clearly intoxicated more than 10 times, based on the question: "Have you ever consumed so much alcohol that you were clearly intoxicated (drunk)?", with five categories ranging from 'No, never' to 'Yes, more than 10 times'. There were $\mathrm{n}=147$ missing responses on the intoxication item, leaving a sample of $\mathrm{N}=9056$ for this measure. In addition, potential alcohol and drug problems were identified employing the six-item inventory CRAFFT. ${ }^{30}$ CRAFFT was specifically designed to identify alcohol and illicit drug problems among adolescents, ${ }^{30}$ and have been shown to have acceptable sensitivity and specificity at a cut-off of $\geq 2$ in international studies. ${ }^{31} 32$ In relation to the ung@hordaland sample, a linear relationship between CRAFFT score and excessive alcohol consumption, frequency of intoxication and debut of illicit drug use has previously been reported. ${ }^{32}$ In the current study, $28.4 \%$ of those having tried alcohol were CRAFFT-positive, while $61.1 \%$ of those having tried illicit drugs were CRAFFT-positive.

\section{Mental health problems}

Symptoms of depression, anxiety and ADHD were included as the main dependent variables. Depression was assessed using the short version of the Mood and Feelings Questionnaire (SMFQ) ${ }^{33}$ The SMFQ comprises 13 items assessing depressive symptoms rated on a 3-point scale. The wordings of the response categories in the Norwegian translation equal the original categories of 'Not true', 'Sometimes true' and 'True'. High internal consistency between the items and strong unidimensionality has been shown in population-based studies, ${ }^{34}$ and was recently confirmed in a study based on the sample included in the present study. ${ }^{35}$ For the purposes of the current study, depression was defined as a score above the 90th centile of the total SMFQ score. It should be noted that term depression as used in the current study does not imply existence of a clinical diagnosis, such as major depressive disorder (MDD). Also, being a relatively brief self-report questionnaire, the SMFQ does not differentiate between different types of depressive disorders/conditions. The Cronbach's $\alpha$ of the SMFQ in the ung@hordaland sample was 0.91 .

Symptoms of anxiety were identified using the five-item inventory SCARED, which is short form of the 41-item version screening inventory for anxiety disorders. ${ }^{36}$ The short form of the SCARED has showed similar psychometric properties to the full version.

Symptoms of inattention and hyperactivity were measured using subscores from the official Norwegian translation of the Adult ADHD Self-report Scale (ASRS), ${ }^{37}$ originally constructed for use in adults, but recently validated among adolescents. ${ }^{38}$ ASRS is an 18-item self-report scale, comprising 9 items on a hyperactivity-impulsivity subscale and 9 items on an inattention subscale. The responses are given on a 5-point scale (ranging from 'Never' to 'Very often').

\section{Statistical analysis}

Five different alcohol and drug-related binary variables were constructed as main independent variables: ever consumed alcohol (Yes/No), ever tried illicit drugs (Yes/No), those reporting $\geq 90$ th gender-specific centile alcohol consumption (Yes/No), intoxication $>10$ times (Yes/No) and CRAFFT-positive according to the $\geq 2$ cut-off (Yes/No). For dependent variables the mental health questionnaires were dichotomised at the 90th centile, identifying those with high sum scores on the ASRS subscales of inattention (raw score range for cutpoint 24-36, mean 27.2) and hyperactivity-impulsivity (raw score range for cut-point 20-36, mean 22.9), the SMFQ scale of depression (raw score range for cut-point 15-26, mean 19.3) and the SCARED scale of anxiety (raw score range for cut-point 5-10, mean 6.2).

First, the sample was described in relation to the independent variables, stratified for age and gender. Second, ORs were computed using crude logistic regression models for the associations of interest, as well as logistic regression models adjusted for age and gender and then adjusted for age, gender and SES, with mental health variables analysed separately and collectively (i.e. entered into the same logistic regression model). In addition, as previous studies have shown differential age and gender effects in the development of mood disorder, anxiety disorder, behaviour disorder and 
substance-use disorders among adolescents, ${ }^{1}$ we investigated the potential two-way interaction between age and gender for alcohol-related and drug-related variables in relation to mental health problems. The presence of significant interactions was assessed using likelihood-ratio tests (Wald). When significant interactions were identified, the associations of interest were presented stratified for age or gender. In secondary analyses, we investigated the association between the spectrum of alcohol consumption ('Never tried alcohol', 'Non-consumption', '0.1-19.9th', '20.0-79.9th', '80.0-89.9th', '90.0-100th') and frequency of intoxication ('Never tried alcohol', 'Never intoxicated', 'Once', '2-3 times', '4-10 times' and '>10 times') with categories separately for all mental health variables, employing age-adjusted and genderadjusted logistic regression models with 'Never tried' as the reference group. All analyses were performed using Stata V.12.0. ${ }^{39}$ Owing to missing information on the frequency of intoxication question, analyses involving this variable only included $n=9056$ participants. Frequency of intoxication was included as an independent variable in order to retain as much information as possible.

\section{RESULTS}

The final sample consisted of $\mathrm{N}=9203$ participants, where $54.3 \%$ were female and the mean age was 17.9 (SD 0.8 ) years. Table 1 and figures 1 and 2 show the use of alcohol and illicit drugs stratified by age and gender. A total of $20.7 \%$ of the girls and $27.1 \%$ of the boys had not tried alcohol, whereas $8.8 \%$ of the girls and $12.5 \%$ of the boys had tried any illicit drug. Among the participants aged 17, 35.3\% had not tried alcohol, compared with $16 \%$ aged 18 or more $(\mathrm{p}<0.001)$. Also, $\sim 22 \%$ of the samples were CRAFFT-positive, indicating some alcoholrelated or drug-related problem. There was a significant age trend for all independent variables for both genders, where increasing age was associated with increased proportion of participants having tried alcohol or illicit drugs, as well as reporting alcoholrelated and drug-related problems ( $\mathrm{p}$ values ranging from 0.002 to $<0.001$ ).

Table 2 depicts the crude, age-adjusted and genderadjusted, and age-adjusted, gender-adjusted and SES-adjusted associations between having tried alcohol, illicit drugs or reporting alcohol-related and drug-related problems in relation to mental health problems. Having ever consumed alcohol was associated with increased odds of all mental health problems in crude and age-adjusted and gender-adjusted models, except for symptoms of anxiety (crude ORs ranging from 1.13 to 2.36). Having ever tried illicit drugs was associated with increased odds of all mental health problems in crude and age-adjusted and gender-adjusted models (crude ORs ranging from 1.33 to 2.38). In relation to alcohol-related and drug-related problems, being CRAFFT-positive was associated with increased odds of all mental health problems in the crude and age-adjusted and gender-adjusted model (crude ORs ranging from 1.68 to 3.24). Excessive alcohol consumption was associated with all mental health problems in crude and age-adjusted and gender-adjusted models (crude ORs ranging from 1.61 to 2.70). Frequent intoxication was associated with increased symptoms of depression, inattention and hyperactivity in both regression models, but not with symptoms of anxiety (ORs ranging from 0.95 to 2.08). Further adjustment for self-

\begin{tabular}{|c|c|c|c|c|c|c|}
\hline & $\begin{array}{l}\text { Total sample } \\
\%(95 \% \mathrm{Cl})\end{array}$ & $\begin{array}{l}\text { Born } 1995 \\
\%(95 \% \mathrm{Cl})\end{array}$ & $\begin{array}{l}\text { Born } 1994 \\
\%(95 \% \mathrm{Cl})\end{array}$ & $\begin{array}{l}\text { Born } 1993 \\
\%(95 \% \mathrm{Cl})\end{array}$ & $\begin{array}{l}\text { OR for age trend } \\
(95 \% \mathrm{Cl})\end{array}$ & p Value \\
\hline \multicolumn{7}{|c|}{ Never consumed alcohol (\% yes) } \\
\hline Girls & 20.7 (19.6 to 21.8$)$ & 31.4 (29.4 to 33.5$)$ & $19.4(17.6$ to 21.4$)$ & $6.3(5.1$ to 7.7$)$ & $0.42(0.38$ to 0.47$)$ & $<0.001$ \\
\hline Boys & 27.1 (25.7 to 28.4$)$ & 39.7 (37.4 to 42.1$)$ & 26.4 (24.2 to 28.7$)$ & $7.6(6.1$ to 9.4$)$ & $0.41(0.37$ to 0.45$)$ & $<0.001$ \\
\hline \multicolumn{7}{|c|}{ Ever tried illicit drugs (\% yes) } \\
\hline Girls & $8.8(8.1$ to 9.6$)$ & 6.1 (5.1 to 7.3$)$ & $8.2(7.0$ to 9.6$)$ & $13.7(11.9$ to 15.6$)$ & 1.57 (1.39 to 1.77$)$ & $<0.001$ \\
\hline Boys & 12.5 (11.5 to 13.5$)$ & 10.8 (8.5 to 11.2$)$ & 10.2 (8.8 to 11.9$)$ & 18.5 (16.3 to 21.0$)$ & $1.37(1.22$ to 1.54$)$ & $<0.001$ \\
\hline \multicolumn{7}{|c|}{ 90th centile alcohol consumption* (\% yes) } \\
\hline Girls & 7.7 (6.9 to 8.6$)$ & $6.0(4.8$ to 7.4$)$ & 7.7 (6.4 to 9.2$)$ & $9.7(8.2$ to 11.5$)$ & $1.30(1.13$ to 1.51$)$ & $<0.001$ \\
\hline Boys & $7.4(6.5$ to 8.4$)$ & 5.9 (4.6 to 7.6$)$ & 5.9 (5.5 to 8.5$)$ & 9.6 (7.9 to 11.6$)$ & $1.31(1.10$ to 1.55$)$ & 0.002 \\
\hline \multicolumn{7}{|c|}{ Frequent intoxication $(>10 ; \%$ yes $) \dagger$} \\
\hline Girls & 20.5 (19.4 to 21.6$)$ & $10.6(9.3$ to 12.0$)$ & $19.7(17.9$ to 21.7$)$ & 36.1 (33.6 to 38.8$)$ & $2.20(2.01$ to 2.41$)$ & $<0.001$ \\
\hline Boys & 21.3 (20.1 to 22.6 ) & 10.7 (9.3 to 12.3$)$ & 21.9 (19.9 to 24.1$)$ & 37.1 (34.2 to 40.1$)$ & 2.21 (2.00 to 2.44$)$ & $<0.001$ \\
\hline \multicolumn{7}{|c|}{ CRAFFT-positive ( $\geq 2 ; \%$ yes) } \\
\hline Girls & 23.3 (22.2 to 24.5$)$ & 20.0 (18.3 to 21.8$)$ & 22.4 (20.5 to 24.4$)$ & 29.5 (27.1 to 32.1$)$ & 1.29 (1.19 to 1.40$)$ & $<0.001$ \\
\hline Boys & 20.3 (19.1 to 21.5$)$ & $15.8(14.1$ to 17.6$)$ & $19.3(17.4$ to 21.4$)$ & 29.0 (26.3 to 31.8$)$ & 1.47 (1.34 to 1.62$)$ & $<0.001$ \\
\hline
\end{tabular}




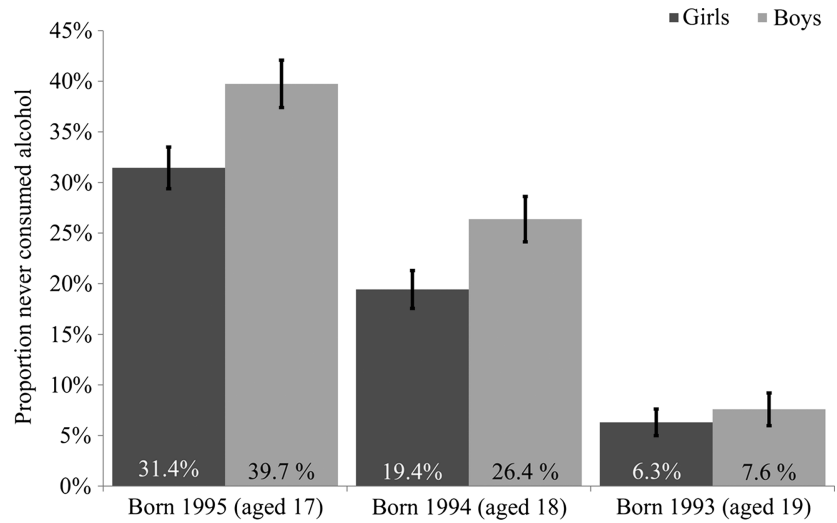

Figure 1 Proportion of participants having never consumed alcohol across gender-stratified age groups $(\mathrm{N}=9203$, girls $n=4995$, boys $n=4208$ ). Error bars represent $95 \%$ Cls.

reported perceived family SES only slightly altered the estimated associations.

Table 3 shows the age-adjusted and gender-adjusted associations between having tried alcohol, illicit drugs or reporting alcohol-related and drug-related problems, in relation to mental health problems analysed collectively. Entering all of the mental health variables into the same logistic regression model substantially attenuated the associations of interest, but the patterns of associations were similar to those obtained by entering them separately.

For the most part, no two-way age and gender interactions across use of alcohol and illicit drugs and mental health problems were found; only seven out of 40 $(17.5 \%)$ investigated interactions were statistically significant (data not shown). For age, significant interactions were found with having ever consumed alcohol and frequent intoxication in relation to hyperactivity $(\mathrm{p}=0.002$ and $\mathrm{p}=0.025$, respectively). In the age-stratified analyses having ever tried alcohol was associated with increased levels of hyperactivity for 17-year-olds ( $\mathrm{OR}=2.53$, CI $95 \%$ 1.88 to 3.43 ) and 18 -year-olds (OR=2.34, CI $95 \% 1.57$ to 3.48 ), but not for 19 -year-olds ( $\mathrm{OR}=0.79$, CI $95 \% 0.47$ to

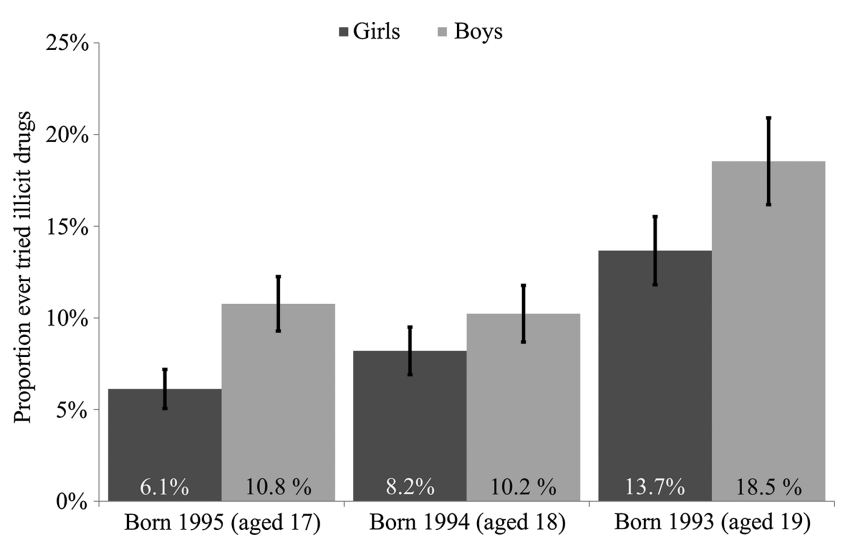

Figure 2 Proportion of participants having ever tried illicit drugs across gender-stratified age groups $(\mathrm{N}=9203$, girls $n=4995$, boys $n=4208$ ). Error bars represent $95 \%$ Cls.
1.34). Frequent intoxication was associated with increased levels of hyperactivity for all age groups, more strongly among 17 (OR=2.56, CI 95\% 1.88 to 3.47) and 18-year-olds ( $\mathrm{OR}=2.54$, CI $95 \% 1.93$ to 3.34) than for 19 -year-olds ( $\mathrm{OR}=1.55$, CI $95 \% 1.16$ to 2.08 ).

For gender, significant interactions were found with having ever tried illicit drugs and excessive alcohol consumption in relation to symptoms of anxiety $(\mathrm{p}=0.021$ and $\mathrm{p}<0.001$, respectively), excessive alcohol consumption and symptoms of hyperactivity $(\mathrm{p}=0.021)$, and with frequent intoxication and excessive consumption and symptoms of depression $(\mathrm{p}=0.027$ and $\mathrm{p}=0.018$, respectively). In the gender-stratified analyses, having ever tried illicit drugs and reporting excessive consumption were associated with increased symptoms of anxiety for boys $(\mathrm{OR}=2.44$, (CI $95 \% 1.57$ to 3.78) and $\mathrm{OR}=4.36$ (CI 95\% 2.52 to 7.57$)$, respectively), but not for girls ( $\mathrm{OR}=1.30$ (CI 95\% 0.98 to 1.73 ) and $\mathrm{OR}=1.23$ (CI 95\% 0.87 to 1.73), respectively). The same pattern was evident for depression, where frequent intoxication was associated with increased symptoms among boys $(\mathrm{OR}=1.83$, CI $95 \%$ 1.32 to 2.52 ) but not for girls (OR=1.19, CI $95 \% 0.98$ to 1.44). Excessive alcohol consumption was associated with increased symptoms of hyperactivity and depression, more strongly for boys (OR=3.78 (CI 95\% 2.65 to 5.40 ) and $\mathrm{OR}=3.57$ (CI 95\% 2.32 to 5.51), respectively) than girls (OR=2.17 (CI 95\% 1.60 to 2.94) and $\mathrm{OR}=1.89$ (CI $95 \% 1.43$ to 2.49 ), respectively).

Table 4 shows the associations between alcohol consumption and frequency of intoxication categories with never having tried alcohol as reference. For symptoms of inattention, hyperactivity and depression, there was a trend towards more symptoms of mental health problems with increasing levels of usual consumption and higher frequency of intoxication (all $\mathrm{p}<0.001$ ). This trend was not found for symptoms of anxiety where there were no associations with intoxication categories ( $p$ value for trend: 0.679 ) and alcohol consumption categories ( $p$ value for trend: 0.061 ). The only significant difference was found between excessive alcohol consumption (90th centile) compared with never having tried alcohol (OR=1.60, CI 95\% 1.15 to 2.23).

\section{DISCUSSION \\ Main findings}

In sum, most adolescents aged 17-19 years had tried alcohol and one-fifth of the girls and one-fourth of the boys had tried some illicit drug. Also, $20 \%$ of the adolescents reported some alcohol-related or drug-related problems, as indicated by 2 or more points on the CRAFFT questionnaire. There was a clear positive age trend for having tried alcohol and illicit drugs for boys and girls, and debut of alcohol and illicit drug use was associated with mental health problems for both genders. Having tried illicit drugs, excessive alcohol consumption and being CRAFFT-positive were associated with all mental health 
Table 2 Logistic regression models of use of alcohol and illicit drugs as risk factor for mental health problems

\begin{tabular}{|c|c|c|c|c|}
\hline & $\begin{array}{l}\text { ASRS inattention } \\
\text { OR }(95 \% \mathrm{CI})\end{array}$ & $\begin{array}{l}\text { ASRS } \\
\text { hyperactivity } \\
\text { OR }(95 \% \mathrm{Cl})\end{array}$ & $\begin{array}{l}\text { SMFQ } \\
\text { OR }(95 \% \mathrm{Cl})\end{array}$ & $\begin{array}{l}\text { SCARED } \\
\text { OR }(95 \% \mathrm{CI})\end{array}$ \\
\hline \multicolumn{5}{|l|}{ Ever consumed alcohol } \\
\hline Crude & 2.36 (1.90 to 2.93$)$ & 2.08 (1.68 to 2.58$)$ & 1.73 (1.43 to 2.09$)$ & $1.13(0.94$ to 1.37$)$ \\
\hline Adjusted for age and gender & 2.21 (1.77 to 2.76$)$ & 2.07 (1.66 to 2.58$)$ & 1.64 (1.35 to 1.99$)$ & $1.03(0.84$ to 1.25$)$ \\
\hline Adjusted for age, gender and & 2.15 (1.72 to 2.69$)$ & 2.03 (1.62 to 2.53$)$ & $1.59(1.31$ to 1.93$)$ & $0.99(0.81$ to 1.21$)$ \\
\hline \multicolumn{5}{|l|}{ socioeconomic status (SES) } \\
\hline \multicolumn{5}{|l|}{ Ever tried illicit drugs } \\
\hline Crude & 2.38 (1.98 to 2.87$)$ & 2.26 (1.86 to 2.74$)$ & 1.69 (1.39 to 2.05$)$ & $1.33(1.05$ to 1.68$)$ \\
\hline Adjusted for age and gender & 2.49 (2.06 to 3.02$)$ & 2.36 (1.94 to 2.89$)$ & 1.98 (1.62 to 2.42$)$ & 1.55 (1.23 to 1.98$)$ \\
\hline Adjusted for age, gender and SES & 2.42 (2.00 to 2.93$)$ & 2.31 (1.90 to 2.82$)$ & 1.91 (1.56 to 2.34$)$ & 1.50 (1.18 to 1.91$)$ \\
\hline \multicolumn{5}{|l|}{ 90th centile alcohol consumption* } \\
\hline Crude & $1.97(1.55$ to 2.51$)$ & $2.70(2.14$ to 3.40$)$ & $2.19(1.74$ to 2.75$)$ & 1.61 (1.21 to 2.14$)$ \\
\hline Adjusted for age and gender & 1.96 (1.54 to 2.50$)$ & 2.76 (2.19 to 3.48$)$ & $2.27(1.79$ to 2.88$)$ & 1.64 (1.22 to 2.19$)$ \\
\hline Adjusted for age, gender and SES & 1.98 (1.55 to 2.53$)$ & 2.77 (2.19 to 3.49$)$ & $2.29(1.80$ to 2.90$)$ & $1.64(1.22$ to 2.20$)$ \\
\hline \multicolumn{5}{|l|}{ Intoxication >10 times $†$} \\
\hline Crude & 1.83 (1.56 to 2.15$)$ & 2.08 (1.77 to 2.45$)$ & $1.30(1.10$ to 1.52$)$ & $0.95(0.78$ to 1.16$)$ \\
\hline Adjusted for age and gender & 1.80 (1.52 to 2.12$)$ & 2.18 (1.84 to 2.59$)$ & $1.36(1.15$ to 1.61$)$ & $0.97(0.79$ to 1.20$)$ \\
\hline Adjusted for age, gender and SES & $1.80(1.52$ to 2.13$)$ & 2.17 (1.83 to 2.58$)$ & $1.35(1.14$ to 1.61$)$ & $0.96(0.78$ to 1.18$)$ \\
\hline \multicolumn{5}{|l|}{ CRAFFT-positive $(\geq 2)$} \\
\hline Crude & 3.15 (2.71 to 3.66$)$ & 3.24 (2.78 to 3.78$)$ & 2.84 (2.46 to 3.28$)$ & 1.68 (1.42 to 1.99$)$ \\
\hline Adjusted for age and gender & $3.06(2.63$ to 3.56$)$ & 3.22 (2.76 to 3.77$)$ & 2.84 (2.45 to 3.29$)$ & $1.62(1.38$ to 1.94$)$ \\
\hline Adjusted for age, gender and SES & 3.01 (2.59 to 3.51$)$ & 3.18 (2.72 to 3.71$)$ & $2.80(2.41$ to 3.25$)$ & $1.59(1.34$ to 1.90$)$ \\
\hline \multicolumn{5}{|c|}{$\begin{array}{l}\text { Mental health variables analysed separately. } \mathrm{N}=9203 \text { (girls } \mathrm{n}=4995 \text {, boys } \mathrm{n}=4208 \text { ). } \\
\text { Significant associations in italic. } \\
95 \text { Cls in parentheses. } \\
\text { CRAFFT: screening tool for identification of problematic alcohol and drug use among adolescents. } \\
\text { ASRS: Adult attention-deficit-hyperactivity disorder (ADHD) Self-report Scale, screening inventory for ADHD. ASRS inattention: the inattention } \\
\text { subscale of the ASRS ( } 9 \text { items). ASRS hyperactivity: the hyperactivity-impulsivity subscale of the ASRS (nine items). } \\
\text { SMFQ: the short version of the Mood and Feelings Questionnaire, screening inventory for symptoms of depression and depressive disorders. } \\
\text { SCARED: five-item screening inventory for symptoms of anxiety and anxiety disorders. } \\
\text { *Only includes those who have tried alcohol ( } n=7031) \text {. } \\
\text { tOnly includes those with valid response on frequency of intoxication ( } n=9056) \text {. }\end{array}$} \\
\hline
\end{tabular}

problems. No J-shaped or U-shaped association was found for alcohol consumption or frequency of intoxication in relation to any of the mental health problems included in this study. There was no clear evidence of any substantial age, gender or SES confounding or modifying effect of age and gender on the estimated association between alcohol-related and drug-related measures and mental health problems.

Table 3 Logistic regression models of use of alcohol and illicit drugs as risk factor for mental health problems, adjusted for age and gender

\begin{tabular}{lllll}
\hline & $\begin{array}{l}\text { ASRS inattention } \\
\text { OR }(95 \% \mathrm{Cl})\end{array}$ & $\begin{array}{l}\text { ASRS hyperactivity } \\
\text { OR }(95 \% \text { Cl) }\end{array}$ & $\begin{array}{l}\text { SMFQ } \\
\text { OR (95\% CI) }\end{array}$ & $\begin{array}{l}\text { SCARED } \\
\text { OR (95\% CI) }\end{array}$ \\
\hline Ever consumed alcohol & $1.83(1.44$ to 2.32$)$ & $1.71(1.35$ to 2.16$)$ & $1.45(1.17$ to 1.78$)$ & $0.79(0.64$ to 0.98$)$ \\
Ever tried illicit drugs & $1.87(1.50$ to 2.32$)$ & $1.74(1.40$ to 2.17$)$ & $1.48(1.18$ to 1.86$)$ & $1.12(0.86$ to 1.46$)$ \\
90th centile alcohol consumption* & $1.24(0.94$ to 1.63$)$ & $2.30(1.78$ to 2.98$)$ & $1.88(1.45$ to 2.44$)$ & $1.18(0.86$ to 1.62$)$ \\
Intoxication $>10 \dagger$ & $1.45(1.20$ to 1.75$)$ & $1.95(1.62$ to 2.35$)$ & $1.18(0.98$ to 1.43$)$ & $0.79(0.63$ to 0.99$)$ \\
CRAFFT-positive $(\geq 2)$ & $1.97(1.66$ to 2.34$)$ & $2.27(1.91$ to 2.69$)$ & $2.17(1.84$ to 2.55$)$ & $0.99(0.82$ to 1.21$)$ \\
\hline
\end{tabular}

Mental health variables analysed collectively. $N=9203$ (girls $n=4995$, boys $n=4208$ ).

Significant associations in italic.

$95 \mathrm{Cls}$ in parentheses.

CRAFFT: screening tool for identification of problematic alcohol and drug use among adolescents.

ASRS: Adult attention-deficit-hyperactivity disorder (ADHD) Self-report Scale, screening inventory for ADHD. ASRS inattention: the inattention subscale of the ASRS (9 items). ASRS hyperactivity: the hyperactivity-impulsivity subscale of the ASRS (nine items).

SMFQ: the short version of the Mood and Feelings Questionnaire, screening inventory for symptoms of depression and depressive disorders.

SCARED: five-item screening inventory for symptoms of anxiety and anxiety disorders.

*Only includes those who have tried alcohol ( $n=7031)$.

tOnly includes those with valid response on frequency of intoxication $(n=9056)$. 
Table 4 Logistic regression models across alcohol consumption and frequency of intoxication categories, 'Never tried alcohol' as reference

\begin{tabular}{|c|c|c|c|c|}
\hline & $\begin{array}{l}\text { ASRS inattention } \\
\text { OR }(95 \% \mathrm{Cl})\end{array}$ & $\begin{array}{l}\text { ASRS hyperactivity } \\
\text { OR }(95 \% \mathrm{Cl})\end{array}$ & $\begin{array}{l}\text { SMFQ } \\
\text { OR }(95 \% \mathrm{Cl}) \\
\end{array}$ & $\begin{array}{l}\text { SCARED } \\
\text { OR }(95 \% \mathrm{CI})\end{array}$ \\
\hline Categories & \multicolumn{4}{|c|}{ Alcohol consumption categories as independent variable } \\
\hline Never consumed alcohol & 1.00 (Reference) & 1.00 (Reference) & 1.00 (Reference) & 1.00 (Reference) \\
\hline Non-consumption & $\begin{array}{l}1.90 \\
(1.45 \text { to } 2.48)\end{array}$ & $\begin{array}{l}1.46 \\
(1.10 \text { to } 1.93)\end{array}$ & $\begin{array}{l}1.43 \\
(1.12 \text { to } 1.82)\end{array}$ & $\begin{array}{l}1.01 \\
(0.78 \text { to } 1.30)\end{array}$ \\
\hline $0.1-19.9$ th centile & $\begin{array}{l}1.61 \\
(1.19 \text { to } 2.17)\end{array}$ & $\begin{array}{l}1.69 \\
\text { (1.25 to } 2.27)\end{array}$ & $\begin{array}{l}1.44 \\
\text { (1.11 to } 1.88)\end{array}$ & $\begin{array}{l}1.00 \\
(0.75 \text { to } 1.32)\end{array}$ \\
\hline 20.0-79.9th centile & $\begin{array}{l}2.15 \\
(1.69 \text { to } 2.74)\end{array}$ & $\begin{array}{l}1.99 \\
(1.56 \text { to } 2.55)\end{array}$ & $\begin{array}{l}1.51 \\
(1.21 \text { to } 1.88)\end{array}$ & $\begin{array}{l}0.90 \\
(0.72 \text { to } 1.14)\end{array}$ \\
\hline 80.0-89.9th centile & $\begin{array}{l}3.77 \\
(2.75 \text { to } 5.17)\end{array}$ & $\begin{array}{l}3.56 \\
(2.59 \text { to } 4.91)\end{array}$ & $\begin{array}{l}2.21 \\
\text { (1.62 to } 3.02)\end{array}$ & $\begin{array}{l}1.39 \\
(0.99 \text { to } 1.96)\end{array}$ \\
\hline $90.0-100$ th centile & $\begin{array}{l}4.16 \\
\text { (3.05 to } 5.68)\end{array}$ & $\begin{array}{l}5.28 \\
\text { (3.91 to } 7.12)\end{array}$ & $\begin{array}{l}3.47 \\
(2.60 \text { to } 4.62)\end{array}$ & $\begin{array}{l}1.60 \\
(1.15 \text { to } 2.23)\end{array}$ \\
\hline$p$ Value for trend & $<0.001$ & $<0.001$ & $<0.001$ & 0.061 \\
\hline $\begin{array}{l}\text { Categories } \\
\text { Never consumed alcohol }\end{array}$ & $\begin{array}{l}\text {-requency ot IntoxI } \\
1.00 \text { (Reference) }\end{array}$ & 1.00 (Reference) & Frequency of intoxication categories as independent variable & 1.00 (Refere \\
\hline Never intoxicated & $\begin{array}{l}1.65 \\
(1.24 \text { to } 2.20)\end{array}$ & $\begin{array}{l}1.35 \\
(1.00 \text { to } 1.81)\end{array}$ & $\begin{array}{l}1.30 \\
(1.00 \text { to } 1.67)\end{array}$ & $\begin{array}{l}1.10 \\
(0.85 \text { to } 1.43)\end{array}$ \\
\hline Once & $\begin{array}{l}1.71 \\
(1.23 \text { to } 2.38)\end{array}$ & $\begin{array}{l}2.06 \\
(1.50 \text { to } 2.82)\end{array}$ & $\begin{array}{l}1.55 \\
\text { (1.16 to } 2.08)\end{array}$ & $\begin{array}{l}1.02 \\
(0.74 \text { to } 1.39)\end{array}$ \\
\hline 2-3 times & $\begin{array}{l}2.00 \\
(1.51 \text { to } 2.63)\end{array}$ & $\begin{array}{l}1.62 \\
(1.21 \text { to } 2.15)\end{array}$ & $\begin{array}{l}1.61 \\
\text { (1.26 to } 2.07)\end{array}$ & $\begin{array}{l}0.88 \\
(0.67 \text { to } 1.16)\end{array}$ \\
\hline 4-10 times & $\begin{array}{l}2.49 \\
(1.90 \text { to } 3.26)\end{array}$ & $\begin{array}{l}2.05 \\
(1.55 \text { to } 2.72)\end{array}$ & $\begin{array}{l}1.85 \\
(1.44 \text { to } 2.36)\end{array}$ & $\begin{array}{l}1.05 \\
(0.81 \text { to } 1.38)\end{array}$ \\
\hline$>10$ times & $\begin{array}{l}3.14 \\
(2.43 \text { to } 4.05)\end{array}$ & $\begin{array}{l}3.36 \\
(2.61 \text { to } 4.33)\end{array}$ & $\begin{array}{l}1.95 \\
(1.54 \text { to } 2.47)\end{array}$ & $\begin{array}{l}0.98 \\
(0.76 \text { to } 1.27)\end{array}$ \\
\hline $\mathrm{p}$ Value for trend & $<0.001$ & $<0.001$ & $<0.001$ & 0.679 \\
\hline
\end{tabular}

Moreover, a closing gender gap on alcohol and drug use was supported.

\section{Strengths and limitations}

The current study holds several strengths. First, it is a large well-defined population-based sample of adolescents. The sample size enabled the investigation of the main effects and the potential interaction effects of age and gender. Second, the data collection is recent and allows for an updated and contemporary insight into the current status of alcohol and drug use, the presence of potential alcohol and drug use problems and associations with mental health problems. Third, the study included different measures of alcohol and drug use, as well as the validated CRAFFT questionnaire for alcoholrelated or drug-related problems. Fourth, we included measures of internalising and externalising mental health problems, using well-validated questionnaires measuring symptoms of depression and anxiety, as well as hyperactivity and inattention symptoms that are part of the ADHD diagnosis.
The current study has also some limitations. First, the study is cross-sectional, and this precludes any causal inference of the estimated associations. Previous findings indicate that mental health problems can be a consequence of alcohol and drug use, be a risk factor for alcohol and drug use or that both are influenced by a common cause. ${ }^{40-42}$ Second, the age range included in the present study is limited, and a wider range would enable a more thorough investigation of age-related effects of alcohol and drug use, and probably also increase the chances of finding any moderating effects of age. ${ }^{43}$ Third, both data on the independent and dependent variables were self-reported, which could lead to bias in reporting, especially under-reporting for the independent variables. Fourth, due to missing information, almost $10 \%$ of the total eligible study population was not included in our analyses. The attrition from the current study could affect generalisability and result in adolescents attending school being over-represented. The problem with non-participation in survey research seems unfortunately to be on the rise. ${ }^{44}$ Official data show that in 2012, 92\% of all adolescents in Norway 
aged 16-18 attended high school, ${ }^{45}$ compared with $98 \%$ in the current study. Based on previous research from the former waves of the Bergen Child Study (the nested within the current study), non-participants have also been shown to have more psychological problems than participants. ${ }^{46}$ It is therefore likely that the prevalence of mental health problems is underestimated in the current study. This could suggest that non-responders also have a higher alcohol and drug consumption, which could bias our sample further. This nonparticipation bias is, however, not likely to reduce the associations of interest substantially. ${ }^{47}$ Finally, the assessment of illicit drugs does not indicate the type of drug tried and its frequency, thus limiting conclusions drawn according to the relation between mental health and more specific drugs or consumption patterns. Finally, the study is based on self-reported questionnaires assessing symptoms of alcohol and drug problems and mental health problems, and multiple information would have been preferable to reduce informant bias and common method bias. Also, self-reported questionnaires do not provide information regarding the existence of a clinical diagnosis, and the lack of a clinical interview in confirming a formal diagnosis is a limitation of the present study.

\section{Interpretation}

The closing gender gap reported in previous studies was partly confirmed by the present study. ${ }^{18}$ Although more girls in the younger age group had tried alcohol, boys showed a pattern of trying illegal drugs more often and there were more boys with problems related to alcohol and drug use, while there were no differences in patterns of problem drinking and frequency of intoxication. The expected age pattern was confirmed with more alcohol and drug use and frequent intoxication with increasing age. Eighteen years is the legal age when adolescents can buy alcohol in Norway, and thus an increase in alcohol use at this age is expected. In the 19-year-olds more than a third reported drinking to intoxication. Although this is a lower rate than reported in a previous population-based Norwegian study, ${ }^{21}$ our findings suggest that this negative alcohol use pattern is frequent among Norwegian adolescents.

There was strong evidence for a co-occurrence of alcohol and drug problems and mental health problems among adolescents, consistent with findings in previous studies. ${ }^{4} 3$ While most studies have focused on drug misuse, we also found that even having tried alcohol or drugs in this age group is a potential indicator of mental health problems for both genders. Owing to the crosssectional design of this study, we could not investigate in the direction of causality. But the relationship between alcohol and drug use and mental health problems in adolescence is probably complex and multidirectional. ${ }^{22} 48$ For instance, mental health problems like impulsivity and hyperactivity may possibly render an adolescent susceptible for using alcohol, but these problems may also be exacerbated by alcohol and drug use. There may also be common aetiological factors that account for an increased risk of mental health problems and alcohol consumption, such as parental alcohol use or social peer network. While ADHD and depressive symptoms were consistently related to alcohol and drug use and misuse, the co-occurrence of these disorders may have impacted the association. In line with this the strength of the association was attenuated when including all of the mental health variables, while the pattern was similar and the associations were still significant. Thus, while co-occurrence of symptoms is frequent, depressive and ADHD symptoms seem to have an independent contribution to the association between mental health and alcohol and drug use.

In general, we found little evidence of a substantial modifying effect of age or gender, which is contrary to some previous studies. ${ }^{21} 24{ }^{25}$ We did, however, find weak evidence for a modifying effect of age and gender for specific mental health domains: there was some evidence for an age-differential association between alcohol and drug variables and symptoms of hyperactivity, where having tried alcohol or frequent intoxication was more strongly associated with symptoms of hyperactivity for younger adolescents. This could be related to a lower level of cognitive and emotional control in early adolescence compared with that at an older age, ${ }^{43}$ increasing the susceptibility to alcohol use, drinking to intoxication and mental health problems.

We also found a gender-differential association between alcohol and drug variables and symptoms of internalising mental health problems, where boys showed more consistent association between alcohol and drug variables and symptoms of anxiety and depression than girls. Interestingly, we found that among girls excessive alcohol consumption was not associated with anxiety and frequent intoxication was not associated with depression. This is contrary to results from a previous Finnish study which found stronger associations between heavy drinking and psychosocial dysfunction among girls than among boys. ${ }^{25}$ One factor that may have impacted on this relationship is the higher rate of depressive symptoms in girls, ${ }^{35}$ and this may be understood in light of the 'gender paradox' where the gender with the lowest prevalence rate will be more severely affected. ${ }^{49}$ The interpretation of the findings concerning interactions should, however, be done with caution as the number of tested interactions $(\mathrm{N}=40)$ were high, and only $17.5 \%$ were significant. Future studies should therefore investigate the reported interactions in other study samples.

In the secondary analyses, we found no indication of any curvilinear relationship between alcohol consumption and frequency of intoxication in relation to mental health problems. This is contrary to previous findings, ${ }^{5-9}$ predominantly from adult populations, and may be an indication of a differential association between alcohol habits and mental health problems in adolescents versus adults. Also, it may be an indication of cohort effects, as 
there is a tendency for lower levels of alcohol consumption and more abstention among adolescents in recent years. ${ }^{50} 51$ Thus, as the abstention group grows, the group also includes more individuals who identify with being abstinent, who have a social network and actively choose abstinence due to an increased focus on education, career or sports. ${ }^{52}$

Overall, there may be multiple reasons for discrepancies between our findings and previous studies. The recency of our data collection in comparison to a decade or so older comparison studies might have impacted the results, especially with regard to the pattern of drug and alcohol use. Also, the assessment of mental health differs across studies, with most other studies using brief general mental health measures.

\section{Clinical implications}

The high rate of alcohol and drug use in underaged adolescents, $10 \%$ having tried illegal substances, as well as a pattern of negative alcohol and drug use characterised by frequent intoxication and drinking large quantities of alcohol, together represent a serious public health concern that emphasises a need for preventive interventions. The strong co-occurrence of mental health and alcohol-related and drug-related problems suggests that assessment of alcohol and drug use and misuse should become an integral part of mental health assessment and interventions, especially in adolescents with depression and ADHD.

In summary, it seems evident that alcohol and drug debut, and the frequency and intensity of alcohol consumption are important and relevant indicators of mental health problems among adolescents. Investigation of the causal nature between alcohol/drug misuse and mental health problems, as well as the access to healthcare and utilisation of healthcare among adolescents who use alcohol and drugs in hazardous ways should be addressed in future studies.

\section{Author affiliations \\ ${ }^{1}$ Division of Mental Health, Department of Public Mental Health, Norwegian Institute of Public Health, Bergen, Norway \\ ${ }^{2}$ Alcohol and Drug Research Western Norway, Stavanger University Hospital, Stavanger, Norway \\ ${ }^{3}$ Regional Centre for Child and Youth Mental Health and Child Welfare, Uni Health, Uni Research, Bergen, Norway \\ ${ }^{4}$ Department of Psychiatry, Helse Fonna HF, Haugesund, Norway \\ ${ }^{5}$ Uni Health, Uni Research, Bergen, Norway \\ ${ }^{6}$ Department of Biological and Medical Psychology, University of Bergen, Bergen, Norway \\ ${ }^{7} \mathrm{~K}$. G. Jebsen Centre for Research on Neuropsychiatric Disorders, Bergen, Norway}

Acknowledgements The authors would like to thank Regional Centre for Child and Youth Mental Health and Child Welfare at Uni Health for making the collection of the data, and making the data available for this study. Furthermore, the authors would like to thank the ung@hordaland project group for their intellectual support of this study. And last but not least the authors thank the participants for their time and effort.

Contributors JCS conceived the initial concept, and performed the initial analyses and literature search. JCS, BS, MH interpreted the initial analyses and wrote the first draft. AJL, KMS and RJ reviewed and revised the initial analyses and first draft, and suggested further analyses, as well as revisions of the first draft. The subsequent drafts were reviewed by all authors, and all authors read and approved the final manuscript. All authors contributed to the revision of the manuscript after peer review.

Funding This research received no specific grant from any funding agency in the public, commercial or not-for-profit sectors.

Competing interests JCS was supported by Alcohol and Drug Research Western Norway, Stavanger University Hospital.

Ethics approval The study was approved by the Regional Committee for Medical Research Ethics in Western Norway.

Provenance and peer review Not commissioned; externally peer reviewed.

Data sharing statement Data for research projects from the population-based ung@hordaland study may be made available at request from Regional Centre for Child and Youth Mental Health and Child Welfare, Uni Health, Uni Research, Bergen, Norway.

Open Access This is an Open Access article distributed in accordance with the Creative Commons Attribution Non Commercial (CC BY-NC 3.0) license, which permits others to distribute, remix, adapt, build upon this work noncommercially, and license their derivative works on different terms, provided the original work is properly cited and the use is non-commercial. See: http:// creativecommons.org/licenses/by-nc/3.0/

\section{REFERENCES}

1. Merikangas $\mathrm{KR}, \mathrm{He} \mathrm{J}-\mathrm{p}$, Burstein $\mathrm{M}$, et al. Lifetime prevalence of mental disorders in U.S. adolescents: results from the National Comorbidity Survey Replication-Adolescent Supplement (NCS-A). J Am Acad Child Adolesc Psychiatry 2010;49:980-9.

2. Ormel J, Raven D, van Oort F, et al. Mental health in Dutch adolescents: a TRAILS report on prevalence, severity, age of onset, continuity and co-morbidity of DSM disorders. Psychol Med Published Online First: 20 Jun 2014.

3. Teesson M, Slade T, Mills K. Comorbidity in Australia: findings of the 2007 National Survey of Mental Health and Wellbeing. Aust N Z J Psychiatry 2009;43:606-14.

4. Costello EJ, Armstrong TD, Erkanli A. Report on the developmental epidemiology of comorbid psychiatric and substance use disorders. National Institute on Drug Abuse, 2000.

5. Rodgers $B$, Korten AE, Jorm AF, et al. Non-linear relationships in associations of depression and anxiety with alcohol use. Psychol Med 2000;30:421-32.

6. Rodgers B, Korten AE, Jorm AF, et al. Risk factors for depression and anxiety in abstainers, moderate drinkers and heavy drinkers. Addiction 2000;95:1833-45.

7. Caldwell TM, Rodgers B, Jorm AF, et al. Patterns of association between alcohol consumption and symptoms of depression and anxiety in young adults. Addiction 2002;97:583-94.

8. Skogen JC, Harvey SB, Henderson M, et al. Anxiety and depression among abstainers and low-level alcohol consumers. The Nord-Trøndelag Health Study. Addiction 2009;104:1519-29.

9. Pape H, Hammer T. Sober adolescence-predictor of psychosocial maladjustment in young adulthood? Scand J Psychol 1996;37:362-77.

10. Upmark M, Möller J, Romelsjö A. Longitudinal, population-based study of self reported alcohol habits, high levels of sickness absence, and disability pensions. J Epidemiol Community Health 1999;53:223-9.

11. Hellandsjø Bu ET, Watten RG, Foxcroft DR, et al. Teenage alcoho and intoxication debut: the impact of family socialization factors, living area and participation in organized sports. Alcohol Alcohol 2002;37:74-80.

12. Brecht M-L, O'Brien A, von Mayrhauser C, et al. Methamphetamine use behaviors and gender differences. Addict Behav 2004;29:89-106.

13. Westermeyer J, Boedicker AE. Course, severity, and treatment of substance abuse among women versus men. Am J Drug Alcohol Abuse 2000;26:523-35.

14. Hser Y-I, Huang Y-C, Teruya C, et al. Gender differences in treatment outcomes over a three-year period: a path model analysis. J Drug Issues 2004;34:419-40.

15. Hernandez-Avila CA, Rounsaville BJ, Kranzler HR. Opioidcannabis- and alcohol-dependent women show more rapid progression to substance abuse treatment. Drug Alcohol Depend 2004;74:265-72. 
16. Haas K. Relationship of gender to licit and illicit drug use among adolescents. Chrestomathy 2004;3:92-100.

17. Opland EA, Winters KC, Stinchfield RD. Examining gender differences in drug-abusing adolescents. Psychol Addict Behav 1995;9:167-75.

18. Keyes KM, Grant BF, Hasin DS. Evidence for a closing gender gap in alcohol use, abuse, and dependence in the United States population. Drug Alcohol Depend 2008;93:21-9.

19. Schwinn TM, Schinke SP, Trent DN. Substance use among late adolescent urban youths: mental health and gender influences. Addict Behav 2010;35:30-4

20. Armstrong TD, Costello EJ. Community studies on adolescent substance use, abuse, or dependence and psychiatric comorbidity. $J$ Consult Clin Psychol 2002;70:1224-39.

21. Strandheim A, Holmen TL, Coombes L, et al. Alcohol intoxication and mental health among adolescents-a population review of 8983 young people, 13-19 years in North-Trøndelag, Norway: the Young-HUNT Study. Child Adolesc Psychiatry Ment Health 2009;3:18.

22. Trim RS, Meehan BT, King KM, et al. The relation between adolescent substance use and young adult internalizing symptoms: findings from a high-risk longitudinal sample. Psychol Addict Behav 2007:21:97-107.

23. McCarty CA, Wymbs BT, King KM, et al. Developmental consistency in associations between depressive symptoms and alcohol use in early adolescence. J Stud Alcohol Drugs 2012;73:444-53.

24. Verdurmen J, Monshouwer K, van Dorsselaer S, et al. Alcohol use and mental health in adolescents: interactions with age and gender -findings from the Dutch 2001 Health Behaviour in School-Aged Children Survey. J Stud Alcohol Drugs 2005;66:605-9.

25. Laukkanen ER, Shemeikka SL, Viinamäki HT, et al. Heavy drinking is associated with more severe psychosocial dysfunction among girls than boys in Finland. J Adolesc Health 2001;28:270-7.

26. Theunissen M-J, Jansen M, van Gestel A. Are mental health and binge drinking associated in Dutch adolescents? Cross-sectional public health study. BMC Res Notes 2011:4:100.

27. Torikka A, Kaltiala-Heino R, Rimpelä A, et al. Depression, drinking, and substance use among 14- to 16-year-old Finnish adolescents. Nord J Psychiatry 2001:55:351-7.

28. McLeod JD, Uemura R, Rohrman S. Adolescent mental health, behavior problems, and academic achievement. J Health Soc Behav 2012:53:482-97.

29. Skogen JC, Overland S, Knudsen AK, et al. Concurrent validity of the CAGE questionnaire. The Nord-Trøndelag Health Study. Addict Behav 2011;36:302-7.

30. Knight JR, Shrier LA, Bravender TD, et al. A new brief screen for adolescent substance abuse. Arch Pediatr Adolesc Med 1999;153:591-6.

31. Knight JR, Sherritt L, Harris SK, et al. Validity of brief alcoho screening tests among adolescents: a comparison of the AUDIT, POSIT, CAGE, and CRAFFT. Alcoholism 2003;27:67-73.

32. Skogen JC, Bøe T, Knudsen AK, et al. Psychometric properties and concurrent validity of the CRAFFT among Norwegian adolescents. Ung@ hordaland, a population-based study. Addict Behav 2013;38:2500-5.

33. Thapar A, McGuffin P. Validity of the shortened Mood and Feelings Questionnaire in a community sample of children and adolescents: a preliminary research note. Psychiatry Res 1998;81:259-68.

34. Sharp C, Goodyer IM, Croudace TJ. The Short Mood and Feelings Questionnaire (SMFQ): a unidimensional item response theory and categorical data factor analysis of self-report ratings from a community sample of 7-through 11-year-old children. J Abnorm Child Psychol 2006;34:379-91.

35. Lundervold AJ, Breivik K, Posserud MB, et al. Symptoms of depression as reported by Norwegian adolescents on the Short Mood and Feelings Questionnaire. Front Psychol 2013;4:613.

36. Birmaher B, Brent DA, Chiappetta L, et al. Psychometric properties of the screen for child anxiety related emotional disorders scale (SCARED): a replication study. J Am Acad Child Adolesc Psychiatry 1999;38:1230-6.

37. Kessler RC, Adler LA, Gruber MJ, et al. Validity of the World Health Organization Adult ADHD Self-report Scale (ASRS) Screener in a representative sample of health plan members. Int J Methods Psychiatr Res 2007;16:52-65.

38. Adler LA, Shaw DM, Spencer TJ, et al. Preliminary examination of the reliability and concurrent validity of the attention-deficit/ hyperactivity disorder self-report scale v1.1 symptom checklist to rate symptoms of attention-deficit/hyperactivity disorder in adolescents. J Child Adolesc Psychopharmacol 2012;22:238-44.

39. StataCorp, Statistical Software: Release 12.0. 2012, Stata Corporation: College Station, TX.

40. Tapert SF, Caldwell L, Burke C. Alcohol and the adolescent brain: human studies. Alcohol Res Health 2004:28:205-12.

41. Chassin L, Pitts SC, DeLucia C, et al. A longitudinal study of children of alcoholics: predicting young adult substance use disorders, anxiety, and depression. J Abnorm Psychol 1999;108:106-19.

42. Sher KJ, Walitzer KS, Wood PK, et al. Characteristics of children of alcoholics: putative risk factors, substance use and abuse, and psychopathology. J Abnorm Psychol 1991;100:427-48.

43. Willoughby T, Good M, Adachi PJC, et al. Examining the link between adolescent brain development and risk taking from a social-developmental perspective. Brain Cogn 2013;83:315-23.

44. Morton SMB, Bandara DK, Robinson EM, et al. In the 21st century, what is an acceptable response rate? Aust $N Z J$ Public Health 2012;36:106-8.

45. The Directorate of Integration and Diversity (IMDi), [Education participation in high schools]. 2012. http://www.imdi.no/no/ Fakta-og-statistikk/Fakta-og-statistikk/Utdanning/?tab=chr

46. Stormark KM, Heiervang E, Heimann M, et al. Predicting nonresponse bias from teacher ratings of mental health problems in primary school children. J Abnorm Child Psychol 2008;36:411-19.

47. Knudsen AK, Hotopf M, Skogen JC, et al. The health status of nonparticipants in a population-based health study: the Hordaland Health Study. Am J Epidemiol 2010;172:1306-14.

48. O'Neil KA, Conner BT, Kendall PC. Internalizing disorders and substance use disorders in youth: comorbidity, risk, temporal order, and implications for intervention. Clin Psychol Rev 2011;31:104-12.

49. Loeber R, Keenan K. Interaction between conduct disorder and its comorbid-effects of age and gender. Clin Psychol Rev 1994; 14:497-523.

50. Danielsson A-K, Wennberg P, Hibell B, et al. Alcohol use, heavy episodic drinking and subsequent problems among adolescents in 23 European countries: does the prevention paradox apply? Addiction 2012;107:71-80.

51. Hibell B, Guttormsson U, Ahlström, S, et al. Summary: the 2007 ESPAD report among students in 35 countries. Luxembourg: European Monitoring Centre for Drugs and Drug Addiction, 2009.

52. Hoel S, Eriksen BM, Breidablik HJ, et al. Adolescent alcohol use, psychological health, and social integration. Scand J Public Health 2004;32:361-7. 